\title{
Research on PPP Mode in Ecological Governance in China
}

\author{
Pingping Sun*, Chong Ren \\ University of Science and Technology of China, Hefei, China \\ Email: *luckspp@mail.ustc.edu.cn
}

How to cite this paper: Sun, P.P. and Ren, C. (2017) Research on PPP Mode in Ecological Governance in China. Open Journal of Social Sciences, 5, 175-187.

https://doi.org/10.4236/jss.2017.56016

Received: April 11, 2017

Accepted: June 17, 2017

Published: June 20, 2017

Copyright $\odot 2017$ by authors and Scientific Research Publishing Inc. This work is licensed under the Creative Commons Attribution International License (CC BY 4.0).

http://creativecommons.org/licenses/by/4.0/

\begin{abstract}
The research explores the cause of the inefficiency of the traditional ecological management model by analyzing the fragmentation of internal governance structure and the marginalization of external governance subjects. Then, on the basis of the core concept of PPP model, taking the current new normal economy into consideration, the research analyzes the necessity and feasibility of introducing the PPP model in the field of ecological governance in china. Finally, the implementation path of the ecological management PPP model is discussed in three aspects-the promotion for the implementation of the PPP project, risk management in PPP project and performance evaluation of PPP project.
\end{abstract}

\section{Keywords}

Ecological Governance, PPP Mode, New Normal, Project System

\section{Introduction}

With the transfer of industrial civilization to ecological civilization, the topic on how to achieve effective ecological governance has always been the core issue common concern to all sectors of society. Traditionally, the government has become the main means to solve the market failure in ecological management. However, due to the "fragmentation" inside governance organizations and the rational limitation of the single governance subject, the effect of government governance is inevitably abnormal and unsustainable. Under the background of the new normal in economy development along with the Ecological Civilization promoted to the level of national strategy in China, social capital is called for making more huge difference in ecological governance. In the point of the view of the new public management theory, PPP mode can be the efficient way for social capital participating in the practice of ecological governance. PPP mode 
(Public-Private Partnerships), making full use of the decisive role of the market in the allocation of resources and the guiding role of the government in the economy, can not only enhance the advantages of both sides, but also improve the efficiency of ecological governance. Therefore, the research analyzes the necessity and feasibility of introducing the PPP mode into the field of ecological governance under the new normal situation, and discusses the implementation path of the mode.

\section{Traditional Mode in Ecological Governance}

The ecological environment resource is a kind of typical quasi-public goods, which has the characteristics of non exclusiveness and competition, so it is hard for market to achieve the provision solely. The indivisible nature of the ecological resources also makes it difficult to define its property or the cost of defining too high, as a result, the market mechanism of ecological resources protection and governance cannot be effective, inevitably leading to the market failure. Based on this, many scholars generally believe that the government can and should take coercive measures to avoid the privatization and "free rider" behavior in ecological governance, for the sake of dealing with the dilemma in collective action of ecological governance, refraining from the "communal tragedy". Government regulation is regarded as a kind of effective replacement for the market to manage the externalities of ecology. In 1930s, under the guidance of the Keynesian case, the government was given the subjectivity and legitimacy of ecological environment governance, and environmental regulation policies were gradually favored by all countries. In china, the government-led development strategy left over from the planned economy also made the government coercive mode the mainstream mode in ecological governance.

The government coercive mode refers to the situation where the government is regarded as the only regulatory subject in ecological governance, who takes a series of measures including administrative, economic and other direct or indirect regulations to internalize the social cost caused by economic entities, and economic entities must strictly abide by the mandatory governance system to achieve the effective ecological governance [1]. This mode can make a huge difference in solving the problem of "market failure" in the initial stage, especially in the organization and coordination of the allocation of various types of governance resources, immediate treatment of various types of emergent ecological and environmental problems, the full protection of social equity and so on. However, due to the inability to overcoming the inherent defects of the "fragmentation" inside the governance organizations and the rational limits of a single monopoly, the government coercive mode also fails with low efficiency of governance.

\subsection{Fragmentation inside the Governance Organization}

With the reformation and development of China's economic society, centralized political structure under the planned economy system is gradually broken, along 
with the division of power and the decentralization of decision-making, and the departments have their own unique functional space or "domain". As a result, fragmented governance system leads to the overlap in interests chain, cross of departmental functions even "border conflict", the lack of consistency in policy process, and the lack of public services. Relying on the promotion of central government, the government coercive mode is implemented through the topdown control structure, which leads to the compatible problem among the public goods attributes of the ecological resources, systematicness of the ecological environment and externalities of ecological governance with the management system based on administrative division, as well as the "Pigs' Payoffs" caused by the difference between the central government's interest structure and local government's [2].

Besides, the "fragmentation" shaped by the loose organizational structure and internal friction of power resources in government coercive mode make the formal rules unable to reshape the system power, resulting in the estrangement and conflict between departments and regions, as well as the policy field formed a mutually destructive or prevarication, ultimately leading to the high cost of governance and the abnormal and unsustainable governance efficiency. It is the "fragmentation" inside the governance organization that leads to the people in Ningxia Liupanshan Ecological Migration Project, which began with great vigor and vitality, finally living on themselves.

\subsection{Marginalized Subjects outside the Governance Organizations}

In the traditional ecological governance mode, the government is regarded as the most authoritative spokesperson of the public interest of the whole society. It can exercise the right of governance on behalf of the public's will and interests, and rationally allocate all power, resources and social welfare. From the formulation of macro policy to the supervision of the implementation in micro level, almost all actions are controlled by the omnipotent government, who bears unlimited responsibility and risk in the process of ecological governance. The government is the only monopoly and it is hard for other possible governance subjects, such as private enterprises, autonomous organizations, social organizations, public interest groups and so on, to intervene, in the actual "excluded" or "marginalized" state.

Due to the limited rationality, the government's ability to ecological governance is constrained by the asymmetry of information acquisition and the decentralization of knowledge. The imperfection of the feedback and the response vector makes the control-oriented ecological governance policy universally "anomie" and the ecological public interest demands cannot draw enough attention, so that governance decision-making loses public support, policy implementation delay and deviation showing up. The imbalance in the allocation of ecological government rights do further inhibit the market's enthusiasm on strengthening self-governance through technological innovation, and the end treatment, ignoring the process control, often makes the governance results fall 
into the "N curve dilemma" [3], such as the fleeting "APEC Blue" in Beijing in 2014 and many other cases of governance failure.

On the other hand, the ecological management projects generally have large scale of investment, long service period and weak return ability. Besides, with the economic development and social mobility, the secondary ecological crisis is also increasing the cost of governance, as a result, most of the ecological governance projects relying on a single financial operation are faced with accumulation risk in government debt, and the lack of the corresponding external oversight mechanisms and competition mechanisms with haphazard investment in and usage of financial capital make most of the government-led ecological management projects constructed well but managed bad, making it difficult to maintain the continuous operation and creating low performance in overall governance output.

\section{Theoretical Analysis of Introducing PPP Mode into Ecological Governance}

In the field of ecological governance, both the single market governance and single government regulation inevitably have a blind spot of mechanism failure. In view of the quasi-public property attributes of ecological resources and the external effects of ecological governance, some scholars believe that PPP mode (Public-Private-Partnership) can be an ideal way to break the dilemma of ecological governance.

\subsection{PPP Mode}

There has been a lot of research on PPP mode since the PPP mode was developed last century. Law researchers believe that PPP mode is a kind of legal contract relationship (Xu Fei and Song Bo, 2010; Li Yan-jun, 2010; Wang Junhao and Jin Xuanxuan, 2016) [4] [5] [6], and Economic researchers regard he PPP mode as an economic system (Liu Zhi, 2005; Yang Wei-hua et al., 2014) [7] [8]. In the field of management, researchers argue that PPP mode is the management in whole lifestyle of the project (Ke Yong-jian et al., 2008; Ye Xiao-su et al., 2016) [9] [10]. Besides, Sociological researchers believe that PPP mode is a consortium of different stakeholders (Hodge et al., 2005; Klijn and Teisman, 2000) [11] [12].

In this paper, researchers agree with the point of view that "Public Private Partnership" refers to the long-term cooperation between the government and the social capital in the field of infrastructure and public services [13]. Based on granting of franchise rights, PPP mode is shaped by benefit sharing and risk sharing, which makes full use of the advantages of both sides to improve the quality and efficiency of the supply of public goods or services, through the introduction of market competition mechanism as well as the incentive and restraint mechanism. In PPP mode, most of the work in design, construction, operation and maintenance of infrastructure is generally done by the social capital, who gets a reasonable return on investment through the "user fees" and the ne- 
cessary "government fees". Accordingly, the government departments are responsible for the supervision on the price and quality of infrastructure and public service, ensuring the maximum public interest. The decision to use PPP mode instead of the government's traditional investment operations to provide public service projects is generally based on the VfM principle (Value for Money). And the selection of the specific paradigm in PPP project relies on the project area, financing needs, expansion needs, fee pricing mechanism, investment income level, the basic framework of risk allocation and the disposal of expiry.

Based on the respect to the market choice, PPP mode promotes the cooperation between the government and social capital, combining the decisive role of the market in the allocation of resources and the guiding role of the government in the development of economy together. It can not only integrate social resources, revitalize the stock of social capital, stimulate private investment and expand the enterprise development space to enhance the economic growth momentum, but also alleviate the financial pressure of the government, strengthening the government's public service function to achieve the best effect of meeting the public interest.

Since the 1990s, the British government has taken the lead in applying the PPP mode to transportation, electricity, water supply, sewage/waste disposal, education, health, national defense, social housing, prisons, police and other fields of public services to address the dual pressures from economic recession and public expenditure, followed by Spain, Australia, the United States, France, Canada and other Western countries [13].

PPP mode has gradually become an important mode of operation on the implementation of multi agent cooperation in the modern public domain. Under the support and guidance of national policy, China is also trying to actively promote PPP mode in the fields of infrastructure, public service, ecological protection and environmental resources [14].

\subsection{Analysis on the Necessity of Introducing PPP Mode into Ecological Governance in China}

PPP mode is a kind of the cooperation between the private sector and the public sector, accompanied by the diversification of public project needs. After the implementation of the tax system reform, China's fiscal transfer payment flexibly making a difference beyond the administrative hierarchy system, adopting the project system. The "project economy" becomes the incentive mechanism to mobilize the local government, and the public project becomes an efficient way to resolve the pressure of the economic growth, improve the investment distribution and realize technical governance in public service. On the one hand, public projects achieve specific project objectives on the basis of matter oriented principle. On the other hand, it helps to achieve the policy objectives delivering the national will through the establishment of norms and models.

Therefore, in China, the ecological governance policy is also implemented through the ecological governance project, including the management of nature reserves, wildlife protection, wild plant protection and protection of other natu- 
ral ecology, as well as water pollution control, air pollution control, solid waste management, hazardous waste treatment, radioactive waste management and other pollution control and environmental management. According to the data released by the National Bureau of Statistics, since the major ecological construction projects were carried out at the end of the twentieth century, such as returning farmland to forest, returning farmland to grassland, natural forest protection, three major projects for shelter belt construction in North and Beijing-Tianjin sandstorm source management, China's ecological governance project has been in the peak period of investment and construction. In recent ten years, the number of each year's new projects on fixed assets investment alone in the field of environment management industry has doubled. ${ }^{1}$

Although there is a benign interaction between the construction of public projects and the development of national economy, the "matching funds" rule makes the input of public projects bring serious collective debt crisis to the grassroots society [15]. Under the background of new normal, government fiscal revenue growth slows down, and local government struggles to resolve debt. So it is urgent to create diversified financing channels and seek new financing mode in the field of ecological governance.

The nature of the ecological governance project is a kind of contractual organization formed by the coordination of state power and private rights on the coordination of ecological public interest. Compared to other public projects, the "incomplete contract" features of the ecological governance project is more obvious due to the complexity of ecological system, the spillover of ecological damage and ecological benefits and the asymmetry of information acquisition [16]. Besides, the ecological compensation mechanism in China is not perfect, resulting in the project funds mainly relying on the central fiscal transfer payment being not able to cover all the ecological compensation investment, further, there is the obvious imbalance in the distribution of ecological benefits, and the participation will of other ecological governance subjects is not strong, leading to the separation of the development and protection, the obstruction in the implementation of ecological governance policy, and gradually raised project transaction cost. Once the PPP mode is introduced, the ecological compensation can be improved by leveraging the social capital to meet the public's persistently growing needs for ecological governance. Moreover, combining the management efficiency and technological innovation of social capital with the development planning and market supervision functions of the governments, the reasonable allocation of ownership and management rights in ecological governance projects can be achieved, forming a more complete contract organization system, improving project management performance, and achieving the restoration, reconstruction and maintenance of ecosystems.

\subsection{Analysis on the Feasibility of Introducing PPP Mode into Ecological Governance in China}

The quasi-public goods attributes of ecological environment resources weakens

${ }^{1}$ Source: National Bureau of Statistics website. 
the asset specificity of ecological management projects, which provides the contract basis for the implementation of PPP mode [17]. And the social capital stock and environment policies under the background of new normal in China do provide more opportunities for the introductions of PPP mode into the field of ecological governance.

Under the background of new normal, overcapacity leads to a large number of idle social capitals, as a result, resource-based social capital needs to withdraw from the development of resources to achieve transformation and upgrading. At the same time, the main traditional transformation destination, the real estate industry, is in the state of excessive stock, where there are high risk and uncertainty, while the huge field of ecological construction and governance is able to provide a broad investment space and capacity, so green development can undoubtedly be the common point of convergence between the government and the enterprise, and investment in environmental protection industry and ecological governance projects can be one of the best way of getting the energybased capital out of the predicament to achieve transformation and upgrading.

In addition, before the age of new normal, Chinese economy has been keeping rapid development, along with the huge accumulation of private wealth, the rising of national savings rate rising and the huge investment potential in private capital. Driven by the profitability characteristics, private capital is to fight for the investment opportunity in ecological governance. Therefore, the combination of ecological capital, industrial capital and financial capital in PPP mode can guide the social capital to participate in ecological management to optimize the comprehensive development of ecological resources, which will be more conducive to the realization of ecological reconstruction.

The national policy support for social capital investment in infrastructure and public services also create a better institutional and policy environment for the introduction of the PPP mode. In recent years, China has issued a series of policy documents to promote and encourage the investment of social capital, such as the "Guidance of the innovation of the financing mechanism in key areas to encourage social investment", "the Ministry of Finance on the promotion of the use of government and social capital cooperation mode related issues notice", "government and social capital cooperation mode operation guidelines (Trial)" and other policy documents, which provides policy support and basis for the development of PPP mode, and clearly points out that on the basis of strengthening the guidance of national policy, measures must be carried out to promote the PPP mode introduced into the field of infrastructure, public services, ecological protection, environmental resources and so on, and standardize the operation of introducing the social capital and right partners to strengthen the ability of supply of social public products. In the phase of promotion of the PPP mode, the relevant guidelines, opinions and the PPP policy documents issued by all provinces also provide technical guidance and specific institutional guarantee for the social capital to participate in government projects. At the same time, the PPP project library established by Ministry of Finance also provides cases refer- 
ences for the practice of PPP mode introduced into the field of ecological governance.

\section{Implementation Path of PPP Mode in Ecological Governance}

PPP ecological governance mode is a kind of relationship contract between the government and the social capital, in which the trade-off of ecological interests among all governance subjects determines the feasibility of the establishment of contractual relationship, and the control and management of various risks determines the dynamic adjustment and maintenance of relationship, the project's governance performance affecting the further promotion and application of the contract relationship in the field of ecology. Based on this, the PPP mode in ecological governance needs to follow a specific implementation path to continuously conduct the ecological governance activities.

\subsection{The Promotion for the Implementation of the PPP Project}

Due to the profit-seeking nature, it is hard for the social capital to invest in the single non-operating ecological governance project, which is shaped by the attributes including a huge sum of initial investment, long payback period, complicated project risk factors and high uncertainty in income. Faced with such difficulties as failure in the financing of the low-profit and purely public welfare ecological projects and resource waste caused by the traditional nomadic management, ecological governance PPP projects should take the mode of regional packing, based on the principle of "bundled and combined development", to encourage the social capital to invest in all ecological PPP projects. Specifically, in each unit formed in the range of county, the most basic level of state governance, non-operating ecological governance projects, where there are strong public welfare but low profit margins, are bundled with the operating projects, where there are huge some of benefits but relatively weak public welfare. Promote the construction and operation of the former projects with the attractiveness from the high profit in the latter, so that the profits of the overall ecological governance projects can reach a reasonable level.

During the phase of project procurement, the project implementing agency can encourage the social capital partner with the project combination, allowing the social capital to participate in the multiple governance projects simultaneously in the county area, and appealing for taking full advantage of the geographical advantage to optimize the regional comprehensive development of ecological resources, innovate the mode of ecological governance, support the rapid development of environmental industry and cultivate highly profitable ecological-industry base, through the linkage effect of multiple projects, promoting good interaction among economic benefits and ecological benefits with social benefits to maximize the ecological public interests and ecological governance efficiency.

PPP mode can broaden the financing channels for public projects, but gov- 
ernment subsidies are still needed for the sake of more and better ecological benefits, due to the attributes of the public welfare properties in ecological management projects. It is necessary for the local governments to fully demonstrate its financial capacity when making such promises as tax incentives, financial subsidies, government payment and so on to social capitals, taking the financial expenditure, government debt and other factors in the whole project life cycle into consideration, in case of the failure of PPP project caused by the government dishonesty.

Accordingly, it is necessary for the state to do well in the top-level design through legislation, upgrading the relevant policy documents in the order of law, strengthening the f consistency and continuity of policy constraints, standardizing the government behavior in accordance with the law, to ensure the smooth implementation of PPP mode. Once the rights and obligations of the participants in the project, the assessment and certification of the project, the procedure of implementation and modification of the contract, the procedures of the administrative examination and approval, the government credit guarantee and other major matters are defined in law, PPP projects agencies can conduct an objective evaluation of the government's financial ability and the profit and risk of the project to make a reasonable design of the project structure and application mode, based on the reference to the standards and operational procedures defined in law as well as their professional theoretical knowledge and practice experience, so as to achieve effective "PPP regional packaging", reducing social capital's risk concerns for investing in ecological governance projects.

\subsection{Risk Management in PPP Project}

PPP mode follows the principle of equal cooperation, mutual respect, benefit sharing and risk sharing. Due to the long participation of the project, the long project cycle and the large scale of investment, the risk of ecological management project is extremely complicated, but the success of the project does depend largely on effective management of all types of risks in the PPP mode. Social capital' willingness to bear the project risk will gradually increase along with the deepening the participation in the project (the degree of privatization of the project), so there is a coherent change between these two factors. In addition, the risk tolerance of social capital also greatly determines the choice of specific paradigm of ecological governance PPP project. Therefore, in the preparation phase of the project, the government can identify the potential risk factors of the project through the study of the similar cases in the past or consulting to the experts in this field, based on the thorough study of the project requirements. Then, taking the initial risk distribution results and the social capital risk control into consideration, the best project partners and the specific PPP paradigm of ecological governance projects will be determined. The reasonable distribution of the risk respectively taken by the social capital and the government should be kept down in the terms of the project contract in case of the loss of the project turning up in the course of government repurchase, renegotiation and other 
events caused by the unreasonable risk allocation.

According to the ability of government and social capital to control different risks, the degree of matching between risk sharing and the benefits obtained, as well as the willingness of two sides to take risks, social capital should undertake such business risks as the project design, construction, financing and operation, which could be distributed to either the project company or the contractor suppliers, operators or the bank in some specific aspect. And the government should undertake such risks as the changes in policy and law as well as the lowest demand risk. As for the majeure risk, both the government and social capital should undertake the responsibility by designing such mechanisms as the pricing adjustment, concession period, buffer funds and so on.

In addition, the "incomplete contract" nature of the PPP agreement and the long life cycle of the ecological governance project determine the dynamic risk sharing in PPP project. In the course of the implementation of the project, once the internal or external conditions change, due to the information asymmetry, unequal negotiation ability, interest conflicts among project participants and other factors, negotiations should be redesigned in the contract to adjust the risk sharing pattern and make full use of the advantage and initiative of the government and social capital. The multiple-level agent relationship in PPP project makes the risk sharing system more complex, which requires the formation of the organic unity of the regulatory system, involving the government supervision departments, third departments and the public supervision. Therefore, the whole process of dynamic monitoring on the implementation of the PPP project can be achieved with laws, administrative regulations, property rights constrains and so on, in case of new risk caused by social capital opportunism and rentseeking of government.

\subsection{Performance Evaluation of PPP Project}

The purpose of ecological governance is to restore or rebuild an ecosystem to provide ecological services to the public goods. The process of implementation of ecological governance policy is not only the process of production and provision of public goods, but also the process of government creating public value. That is, the government mobilizes all subjects to participate in ecological governance, improve the ecological protection consciousness, and make the ecological management project realize ecology, economic and social comprehensive value. Therefore, the performance evaluation of the ecological governance project should not only contain the test on the correctness and rationality of project design, based on the ecological result, but also refer to the judgment on the realization of the basic goal of the ecological governance policy, on the basis of the governance process led by government and the relevant parties.

PPP mode introduced the market mechanism into ecological governance, so the advanced management experience and efficient enterprise management ability of the private sector can effectively shorten the construction period of the ecological governance project, save the construction funds and improve the effi- 
ciency of governance. Meanwhile, the government supervises and guides the operation of social capital with public and prospective self, and restricts the profitability of social capital through the project contract terms to ensure that the social capital obtains reasonable profits without objective tilt, so as to achieve the expected targets on ecological restoration and development. In this case, Based on the functional indicators such as project output, cost effectiveness and regulatory effectiveness, it is possible to examine whether the PPP model meets the efficiency-oriented instrumental goals in government performance management.

For the ecological project is the carrier of implementing ecological management policies, its implementation process is just the implementation process of ecological policy, and is also the output process of public management, therefore, the implementation of the project should reflect the attributes of public management, such as efficiency in management, public characters in policy, respect to the subjects in cooperative production, and the sustainability of the policy effect, so as to achieve the public value of the ecological management [18]. Accordingly, the evaluation of ecological governance performance should select the fairness, participation, sustainability and efficiency as the evaluation factors, based on the requirements of public value and the characteristics of ecological policy.

In terms of fairness, the ecological compensation in PPP project should be able to cover all or even exceed the opportunity cost of other ecological governance subjects participating in the process of the implementation and construction of the project, so as to ensure that all subjects can enjoy equal rights and equal ecological governance responsibility, which is the key to the success of a project and its sustainable development. In terms of the participation, for the ecological projects are implemented in a certain geographical area, subjects there should be able to participate in the project planning, implementation, and management more or less, which is directly correlated with their understanding about the project, their willingness to participate in construction and the management and protect of projects. Sustainability is related to the construction and maintenance of the project, which is not only affected by the formulation and implementation of the corresponding reward system in project and the proportion of the government investment in the whole ecological construction project, but also attributed to other subjects' satisfaction with the ecological compensation and their ecological consciousness. And the efficiency of ecological construction projects mainly refers to the project completed on time and enough compensation paid on time to other governance subjects.

\section{Conclusion}

The introduction of PPP mode into the ecological governance is able to broaden the financing channels and bring about the advanced project management experience, which can not only effectively solve the problem of low efficiency of traditional ecological governance, but also provide a broad space for the development of the stock of social capital under the background of the new normal. The 
research demonstrates the necessity and feasibility of introducing PPP mode into China's ecological governance and explores its implementation path. The major contribution of the research is that the present environment of new normal is given more focus and the significance of public value in PPP project is demonstrated. The main innovation of the research is that the method of "PPP regional packaging" is firstly proposed in the implementation of the PPP project. However, the limitation of the research goes to the lack of the demonstration of the specific of PPP modes applied to various ecological governance projects, due to the weakness of the authors' ability to the further theoretical research. In the future, technical means could be used to build models of ecological governance PPP projects to provide more specific theoretical guidance for the practice of ecological governance.

\section{References}

[1] Tian, Q.-S. (2012) Comparative Analysis of Several Eco-Environment Governance Model. Journal of Shaanxi Academy of Governance, No. 4, 52-57.

[2] Yu, M.J. and Liu, C. (2011) The Pigs' Payoffs between Local and Central Governments in Ecological Management and the Solutions. Jiangsu Social Sciences, No. 2, 147- 152.

[3] Wu, X.Z. (2010) Ecological Modernization: Reflection and Reconstruction-On the Mode Choice of Ecological Management in China. Theory and Reform, No. 5, 12-15.

[4] Xu, F. and Song, B. (2010) The Dynamic Incentive and Monitor Mechanism of Government in Public-Private Partnership Projects. Chinese Journal of Management Science, No. 3, 165-173.

[5] Li, Y.-J. (2010) Public-Private-Partnerships and Contractual Governance. Journal of Northwest University for Nationalities (Philosophy and Social Science), No. 1, 100-105.

[6] Wang, J.H. and Jin, X.X. (2016) Contractual Relationship between Government and Private Enterprises and Its Governance under the Public-Private-Partnership Mode-Taking PPP in Urban Infrastructure in China as an Example Research on Economics and Management. No. 3, 62-68.

[7] Liu, Z. (2005) PPP Pattern in China Public Service Fields. Construction Economy, No. 7, 13-18

[8] Yang, W.H., Wang, X.-S. and Zhang, F.-H. (2014) A Research on PPP Mode Selection Paths for Public Projects-Based on the Three-Dimension Framework of Transaction and Cooperation. East China Economic Management, No. 2, 121-126+ 176.

[9] Ke, Y.-J., Wang, S.-Q. and Chen, B.-Q. (2008) Risk Allocation in Infrastructure PPP Project. Construction Economy, No. 4, 31-35.

[10] Ye, X.-S., Qin, D.-D. and Shi, Y.-S. (2016) Research on Public Participation Mechanism in PPP Project. Construction Economy, No. 3, 32-36.

[11] Hodge, G.A. and Greve, C., Eds. (2005) The Challenge of Public-Private Partnerships: Learning from International Experience. Edward Elgar Publishing, Cheltenham.

[12] Klijn, E.H. and Teisman, G.R. (2003) Institutional and Strategic Barriers to Public-Private Partnership: An Analysis of Dutch Cases. Public Money and Manage- 
ment, 23, 137-146. https://doi.org/10.1111/1467-9302.00361

[13] Zhou, Z.-X., Zhang, X.-F. and Zhang, P. (2015) The Existing Problems in the Application of PPP Mode under the New Economic Normality and Their Solution. China Soft Science, No. 9, 82-95.

[14] Shi, Y. and Liu, J. (2015) A Study on the Decision Making of PPP Mode Based Urban Infrastructure Concession. Contemporary Economic Management, No. 6, 18-23.

[15] Qu, J. (2012) Project System: An New System of State Governance. Social Sciences in China, No. 5, 113-130+207.

[16] Yan, L., Yin, Y.-L. and Fan, D.-J. (2004) A Concept Model for Public Project Governance. China Soft Science, No. 6, 130-135.

[17] Li, X. (2009) Incomplete Contract Transaction Cost and Governance Performance. Chinese Public Administration, No. 1, 114-118.

[18] Bao, G. and Wang, X. (2012) Public Value-Based Government Performance Governance: Origin, Structure and Research Questions. Journal of Public Management, No. 2, 89-97+126-127.

\section{Scientific Research Publishing}

\section{Submit or recommend next manuscript to SCIRP and we will provide best} service for you:

Accepting pre-submission inquiries through Email, Facebook, LinkedIn, Twitter, etc. A wide selection of journals (inclusive of 9 subjects, more than 200 journals) Providing 24-hour high-quality service User-friendly online submission system Fair and swift peer-review system Efficient typesetting and proofreading procedure Display of the result of downloads and visits, as well as the number of cited articles Maximum dissemination of your research work

Submit your manuscript at: http://papersubmission.scirp.org/

Or contact jss@scirp.org 